\title{
O papel do Brasil na evolução das Operações de Paz ${ }^{1}$ Brazilian contribution in the peace operations' evolution
}

\author{
DOI: $10.21530 /$ ci.v12n3.2017.667
}

Anselmo de Oliveira Rodrigues ${ }^{2}$

Eduardo Xavier Ferreira Glaser Migon ${ }^{3}$

\section{Resumo}

O presente artigo tem como objetivo revisar a evolução conceitual das operações de paz sob a égide da Organização das Nações Unidas (ONU), destacando a contribuição brasileira no contexto dessas. Para isso, inicialmente, é apresentada a preocupação da sociedade com as questões associadas à paz e à guerra, apresentando a criação da ONU nesse cenário. Ainda na primeira seção, é definida a taxonomia do artigo e seus principais aspectos. Nesse enfoque, o presente trabalho tomou, como base de estudo, as operações de paz ocorridas no período compreendido entre o término da $2^{\text {a }}$ Guerra Mundial e o ano de 2016. Nas quatro seções seguintes, são analisadas as gerações de operações de paz, destacando suas principais características e o papel do Brasil nessa dinâmica, ressaltando os aspectos qualitativos e quantitativos da contribuição brasileira. Na última seção, é realizada uma análise da evolução das missões de paz e a contribuição brasileira nesse processo.

Palavras-chave: Brasil, ONU, missões de paz, segurança internacional.

\section{Abstract}

This article aims to review the conceptual evolution of peace operations under the aegis of the United Nations (UN), highlighting the Brazilian contribution in this context. To this, initially, is presented the society's concern with issues related to peace and war, presenting the creation of the UN in this scenario. Still in the first section, the taxonomy of the article is defined and its main aspects. In this approach, the present study took as a base of study

1 A pesquisa associada ao presente artigo foi conduzida no âmbito do projeto A importância da África para a Segurança e Defesa do Brasil, desenvolvido sob fomento do Programa Álvaro Alberto de Indução à Pesquisa em Segurança Internacional e Defesa Nacional (Pró-Pandiá), iniciativa conjunta CAPES — Ministério da Defesa. Após o encerramento desse, foi finalizada no âmbito do projeto A importância da África para a Segurança \& Defesa do Brasil: passado, presente e futuro das Operações de Paz no continente africano.

2 Programa de Pós-Graduação em Ciências Militares do Instituto Meira Mattos, da Escola de Comando e Estado-Maior do Exército (ECEME), Rio de Janeiro/RJ, Brasil. E-mail: capanselmo98@ig.com.br

3 Programa de Pós-Graduação em Ciências Militares do Instituto Meira Mattos, da Escola de Comando e Estado-Maior do Exército (ECEME), Rio de Janeiro/RJ, Brasil. E-mail: eduardomigon@gmail.com

Artigo submetido em 18/04/2017 e aprovado em 11/12/2017. 
the peace operations that occurred between the end of the Second World War and the year 2016. In the following four sections, the generations of peace operations are analyzed, highlighting their main characteristics and the role of Brazil in this dynamic, highlighting the qualitative and quantitative aspects of the Brazilian contribution. In the last section, an analysis is made of the evolution of mission operations and the Brazilian contribution in this process.

Keywords: Brazil, UN, peace missions, international security.

\section{Introdução}

As questões associadas à dicotomia entre a guerra e a paz vêm sendo estudadas por diferentes áreas do conhecimento, a exemplo da filosofia, ciência política, direito, ciências militares e relações internacionais. Também por diferentes campos de estudos, a exemplo dos estudos de defesa, estudos estratégicos e estudos de área. Desde Hugo Grotius até Norberto Bobbio (MIGON, 2012), passando por Clausewitz (HOWARD, 2002), alargado rol de pensadores e perspectivas tem sido trazido a lume.

Com igual sentido, percebe-se, desde o início do século XX, a contínua preocupação internacional em estruturar e manter uma organização supranacional capaz de cooperar com a busca e fortalecimento da paz internacional. Sob tal razão foi constituída a Liga das Nações (1919), organização internacional no âmbito da qual o Brasil prontamente se fez presente (PINHEIRO DA CUNHA; MIGON; VAZ, 2014) e cujas ações podem ser conhecidas tanto a partir da obra clássica de Howard-Ellis (1928) quanto na análise contemporânea de Pedersen (2015). Sob os mesmos ideais, e poucos anos depois, a Liga das Nações foi substituída pela Organização das Nações Unidas (ONU), organismo internacional que contemporaneamente se dedica, dentre outras, às questões da segurança internacional.

Assim, em 16 de junho de 1945, firmou-se a Carta das Nações Unidas na Conferência de São Francisco. Esse documento conferiu ao Conselho de Segurança das Nações Unidas (CSNU) a responsabilidade pela preservação da paz e da segurança internacionais. Nesse escopo, mesmo não tendo sido prevista na Carta de São Francisco, as operações de paz (OPs) foram idealizadas pela ONU e se tornaram o principal instrumento da organização para a manutenção da paz internacional (REZENDE; AZEVEDO, 2011). 
As missões onusianas tiveram seu início com o término da $2^{\text {a }}$ Guerra Mundial (GM), particularmente no ano de 1948, e se estendem até os dias atuais. Nesse período, a doutrina dessas operações evoluiu de acordo com o ambiente internacional existente em cada época, vindo a sofrer uma série de transformações desde a forma como foi concebida em 1948 até a maneira como está sendo utilizada nos dias atuais (BELLAMY, 2004).

Um dos principais fatores que motivaram a transformação das missões de paz foi a preocupação, crescente, com a proteção das pessoas. Isso fez com que as OPs evoluíssem para uma melhor gestão dos conflitos, e não mais para a simples resolução dos mesmos. $\mathrm{O}$ aspecto humanitário das missões de paz tornou-se central, balizando a concepção de emprego dos profissionais da ONU (KENKEL, 2013).

Em termos metodológicos, e considerando que essa possivelmente seja a parte mais importante de todo o estudo e, portanto, precisa ser apresentada de maneira clara e específica (CRESWELL, 2010), destaca-se o objetivo dessa comunicação de pesquisa, que é o de revisar a evolução conceitual das OPs, destacando a contribuição brasileira no contexto dessas. O Brasil foi escolhido como o caso a ser estudado pela preocupação que o país tem demonstrado, nos últimos anos, em participar efetivamente da agenda de segurança internacional, e a colaboração nas OPs foi uma maneira que o país encontrou para se inserir nessa agenda (AGUILAR, 2015).

Para isso, adotou-se como recorte temporal as missões ocorridas entre o final da $2^{\text {a }}$ GM e o ano de 2016, inclusive. E, como recorte institucional, foram investigadas exclusivamente as missões conduzidas pela ONU, excluindo-se as operaç̃oes sob a égide de outros organismos internacionais.

Assim, a análise foi realizada verificando todas as contribuições em pessoal realizadas pelo Brasil em OPs, abrangendo as participações com grandes efetivos e as participações realizadas sob a forma de Token Troop Contributions. Coleman entende que as Token Troop Contributions podem ser feitas sob três formas: 1) contribuições com pessoal para cargos seniores nas OPs, 2) contribuições com pessoal para cargos de observadores militares nas OPs e 3) contribuições com pessoal em tropas formadas por contingentes de diversos países (COLEMAN, 2013).

A fim de propor uma sistematização e enquadramento conceitual ao estudo das missões de paz, este artigo está estruturado da seguinte forma: inicialmente é apresentada a preocupação da sociedade com as questões associadas à paz e à guerra, destacando a criação da ONU. Na primeira seção ainda são definidos o objetivo e os limites de investigação desse estudo. Nas quatro seções seguintes, 
são analisadas as gerações de OPs, destacando suas principais características e o papel do Brasil nessa dinâmica, ressaltando os aspectos qualitativos e quantitativos da contribuição brasileira. Na última seção, é realizada uma análise da evolução das missões de paz e o papel do país nesse processo.

\section{A $1^{\text {a }}$ Geração das operações de paz}

Logo após a $2^{\text {a }} \mathrm{GM}$, o mundo sentiu a necessidade de criar uma entidade internacional que fosse capaz de estabelecer parâmetros aceitáveis para que a paz pudesse prevalecer entre as nações, ou pelo menos para que os conflitos não atingissem níveis alarmantes (PENNA FILHO, 2004).

Porém, a realidade mundial nessa época freou o ímpeto da ONU, com a Guerra Fria dividindo o mundo em dois blocos antagônicos e travando o processo decisório do Conselho de Segurança das Nações Unidas (CSNU), pois o emprego de força estava condicionado à unanimidade dos cinco membros permanentes: Estados Unidos da América (EUA), ex-União das Repúblicas Socialistas Soviéticas (URSS), China, França e Grã-Bretanha (BOUTROS-GHALI, 1993). Diante dessa realidade, a ONU não conseguiu colocar em prática o que havia idealizado inicialmente para as OPs.

Foi nesse ambiente que surgiu a $1^{\text {a }}$ Geração, em 1948, dividida entre a manutenção de paz mundial e a realidade imposta pelo confronto bipolar no seio da ONU. Assim, o período que engloba o término da $2^{\text {a }} \mathrm{GM}$ e o final da Guerra Fria compreende o surgimento de todas as OPs que atuaram sob o escopo da $1^{\text {a }}$ Geração das operações de paz e que ainda estão em curso atualmente.

O traço marcante na concepção de emprego das OPs estava baseado em não empregar a força nas operações, estando apenas autorizado o uso da força em legítima defesa das tropas da ONU (BRAGA, 2012). Miall alimenta a discussão ao acrescentar que as missões onusianas ocorridas nessa época exerciam a função de monitorar as fronteiras, estabelecendo zonas tampão, depois de ter conseguido o acordo de cessar fogo entre os beligerantes (MIALL, 1999).

Já Kenkel assinala que a principal característica das missões de paz dessa geração estava na implantação de uma força de interposição na linha de frente entre os contendores, reduzindo o contato entre opositores e diminuindo a probabilidade de escalada da crise (KENKEL, 2013). 
Em vista disso, depreende-se que as OPs possuíam três atores basicamente: dois Beligerantes e uma Força de Interposição. Ainda que enquadrados num cenário belicoso, um traço importante se baseava na convergência dos três atores para um mesmo objetivo, que era pôr fim ao conflito por meio de uma resolução política (BELLAMY; WILLIAMS, 2009).

A ONU reforça o conceito anterior ao assinalar que essas missões possuíam objetivo limitado a, tão somente, estabilizar a situação em campo para que houvesse um espaço político no qual fosse possível resolver o conflito por meios pacíficos (DPKO/DFS, 2008). Em vista disso, Cepik e Kuele destacam que as três principais características das missões de paz dessa época são as seguintes: 1) consenso entre as partes envolvidas no conflito, 2) imparcialidade e 3) não uso da força (CEPIK; KUELE, 2015). O gráfico 1 apresenta as missões de $1^{\text {a }}$ Geração:

\section{Gráfico 1: OPs de $1^{\text {a }}$ Geração}

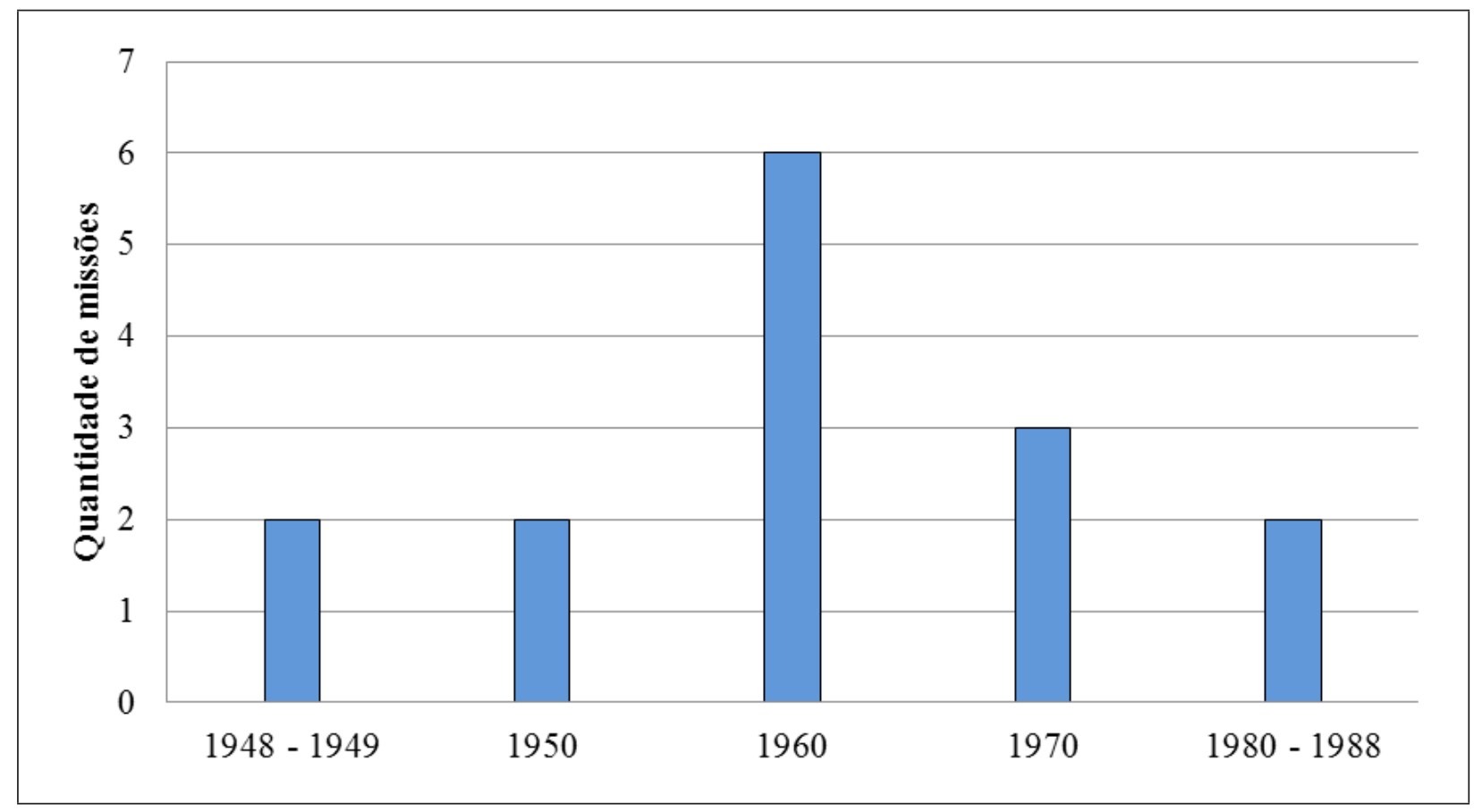

Fonte: elaboração própria, com dados do Departament of Peacekeeping Operations, 2017

Há 15 missões nesse período, sendo 6 na década de 1960. Dessas 15, 5 estão em curso atualmente: 1) UNTSO (United Nations Truce Supervision Organization), 2) UNMOGIP (United Nations Military Observer Group in India and Pakistan), 3) UNFICYP (United Nations Peacekeeping Force in Cyprus), 4) UNDOF (United Nations Disangagement Observer Force) e 5) UNIFIL (United Nations Interim Force in Lebanon). O gráfico 2 esclarece a participação brasileira no período: 


\section{Gráfico 2: Participação brasileira nas OPs de $1^{\text {a }}$ Geração}

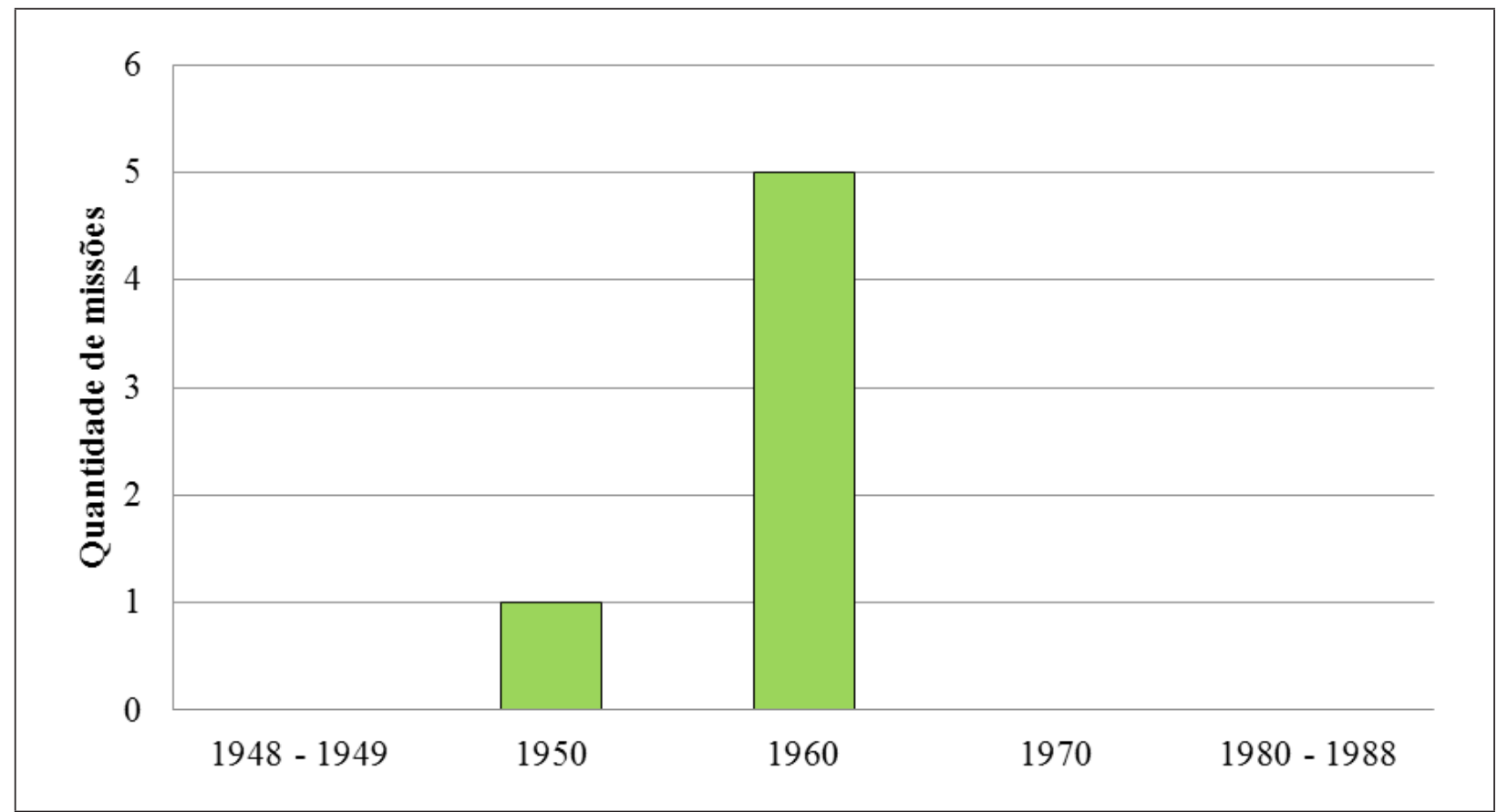

Fonte: elaboração própria, com dados do Departament of Peacekeeping Operations, 2017

Observa-se a participação brasileira em 6 missões nesse período, com 5 delas iniciando-se na década de 1960 e uma em 1956, quando houve o primeiro envio de tropas brasileiras para a região do Sinai, integrando a UNEF I (United Nations Emergency Force), a qual tinha o propósito de manter o cessar-fogo entre os egípcios e os israelenses nessa região (AGUILAR, 2005; FONTOURA, 1999).

A partir de 1967, a contribuição brasileira sofreu uma paralisia, não registrando novas participações nas décadas seguintes. Para que se tenha uma ideia mais detalhada da participação brasileira no período, cabe observar o quadro 1: 
Quadro 1: Participação brasileira em OPs de $1^{\text {a }}$ Geração

\begin{tabular}{|c|c|c|c|c|}
\hline Missão & Localização & Militares & Civis & Período \\
\hline UNEF I & Sinai e Faixa de Gaza & 6.300 & - & $1957-1967$ \\
ONUC $^{4}$ & Congo & 179 & - & $1960-1964$ \\
UNSF5 $^{5}$ & Nova Guiné Ocidental & 2 & - & 1962 \\
DOMREP $^{6}$ & República Dominicana & 1 & - & $1965-1966$ \\
UNIPOM$^{7}$ & Índia/Paquistão & 10 & - & $1965-1966$ \\
UNFICYP & Chipre & 30 & 1 & $1964-$ dias atuais \\
\hline \multicolumn{2}{|c|}{ TOTAL (brasileiros) } & $\mathbf{6 5 2 2}$ & $\mathbf{1}$ & $\mathbf{6 . 5 2 3}$ \\
\hline
\end{tabular}

Fonte: SEITENFUS, 2008; DPKO (Departament of Peacekeeping Operations), 2017.

O destaque fica por conta da UNEF I, missão de paz que mais contou com o envio de brasileiros nesse período. Sobre essa missão, Aguilar assinala que, durante um período de dez anos, o Brasil foi o único país sul-americano que manteve sua contribuição ao longo de toda a missão, enviando anualmente um batalhão de infantaria (batalhão Suez), composto por cerca de 600 homens, perfazendo um total de 6.300 militares que integraram a UNEF I (AGUILAR, 2005). Cumpre destacar também a participação do país no Congo, no âmbito da ONUC.

A participação brasileira não ficou restrita somente aos números - o país teve grande responsabilidade na evolução qualitativa nas missões de paz. Exemplo disso foi a participação do país na ONUC, quando houve o início de um caráter mais humanitário para a dinâmica das OPs, ocasião em que o contingente brasileiro exerceu inúmeras atividades, dentre as quais destacam-se o transporte de gêneros, a atividade de suprimento e até de medicamentos para a população congolesa (NASSER, 2012).

Dando mais ingredientes ao papel do Brasil para a evolução qualitativa das OPs, Kenkel assevera que o país foi o primeiro a enviar um contingente totalmente armado nas missões onusianas. Essa inovação se deu no contexto da UNEF I, marcando uma ruptura com o que estava sendo praticado até então pela ONU. Ou seja, as missões de paz até então se caracterizavam pelo emprego de pequenos grupos de observadores desarmados para monitorar o cessar-fogo entre os beligerantes (KENKEL, 2013).

4 ONUC - United Nations Operation in the Congo.

5 UNSF - United Nations Security Force in West New Guinea.

6 DOMREP - Mission of the Representative of the Secretary-General in the Dominican Republic.

7 UNIPOM - United Nations India-Pakistan Observation Mission. 
O papel do Brasil é ressaltado também por outros autores. Hillen esclarece que, ao enviar tropas armadas para a região do Sinai, o país realizou uma contribuição valiosa para a evolução doutrinária das missões de paz, iniciando uma nova forma de pensar as mesmas (HILLEN, 1998). Assim, confirma-se o caráter inovador ao empregar tropas armadas, o que definiu precedente importante e serviu de base para a evolução das futuras missões (HILLEN, 1998; BELLAMY, 2010; RIKHYE, 1974).

A par dessas contribuições, Kenkel também entende que as missões de

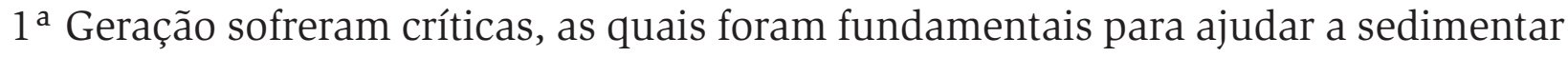
o início da nova geração de missões de paz. A principal crítica está apoiada na natureza passiva e na base rígida na solução pacífica dos conflitos dessas missões, as quais nem sempre atingiram o estado final desejado (KENKEL, 2013).

Diante desse cenário e com o término da Guerra Fria, a ONU voltou a ganhar força nas suas ações, provocando o que muitos chamaram de descongelamento das ações da ONU no sistema internacional. Esse fato fez com que as OPs voltassem a ganhar impulso, desenvolvendo novas formas e novos contornos, aplicando os ensinamentos colhidos nas missões anteriores e proporcionando uma mudança na concepção de emprego dos chamados "capacetes azuis" - as tropas das Nações Unidas. Esse ambiente proporcionou as condições favoráveis para o surgimento da chamada $2^{\text {a }}$ Geração das operações de paz.

\section{A $2^{\mathrm{a}}$ Geração das operações de paz}

O cenário internacional após a Guerra Fria gerou condições para o surgimento de conflitos que não expressavam mais uma rivalidade entre Estados, mas sim uma fricção no ambiente interno estatal, quer seja nas etnias, nas facções e até em grupos de pessoas que não aceitavam mais viver juntos (LA MAISONNEUVE, 1998).

No ambiente internacional, Hillen entende que o término da Guerra Fria gerou um reaquecimento das atividades da ONU, pois o mecanismo de vetos utilizado pelos EUA e pela ex-URSS no contexto bipolar deixou de ser adotado ao término desse período, levando a um aumento da oferta das missões de paz da ONU (HILLEN, 1998).

Diehl concorda com Hillen e nos assevera que essas transformações no mundo resultaram num aumento do emprego de OPs por parte da ONU, com profundas 
mudanças na natureza e na extensão das missões de paz (DIEHL, 2008). Foi nesse sentido que as missões onusianas ganharam um novo impulso e se tornaram a principal ferramenta da ONU para garantir a segurança ao redor do planeta, dando início à $2^{\text {a }}$ Geração das operações de paz, que teve início após a queda do muro de Berlim e se estende até os dias atuais.

Foi nessa atmosfera que o CSNU passou a autorizar missões cada vez mais complexas, abarcando várias funções e atividades e assim surgiram as OPs chamadas de $2^{\text {a }}$ Geração ${ }^{8}$, com mandatos orientados à prestação de ajuda humanitária, verificação da situação dos direitos humanos, policiamento ostensivo, supervisão de eleições, auxílio à administração pública, restauração da infraestrutura e do setor econômico, além dos objetivos tradicionais (BIGATÃO, 2007).

No que concerne às tarefas realizadas por essas missões, Fountoura nos ensina que as missões de $2^{\text {a }}$ Geração tinham como foco a resolução do conflito e a reconstrução do país hospedeiro, incorporando tarefas realizadas por civis e por militares, atuando na reconstrução do país em áreas e setores como eleições, direitos humanos, administração pública, gerenciamento econômico, assistência humanitária, atividades policiais e militares (FONTOURA, 2005).

Posicionando-se oficialmente, a ONU assinala que as missões de paz de

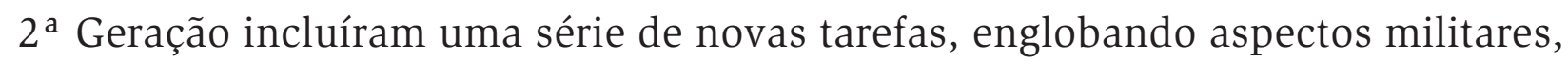
aspectos políticos, preocupação humanitária e com o desenvolvimento do país hospedeiro. A busca por uma paz duradoura, querendo evitar os erros verificados nas OPs de $1^{\text {a }}$ Geração, nortearam as ações da ONU nessa época (DPKO/DFS, 2008).

Em meio a essas mudanças no cenário internacional, o secretário-geral da ONU Boutros Boutros-Ghali elaborou um documento chamado Agenda para a Paz, o qual ampliou as missões de paz sob o ponto de vista conceitual, passando a incluir atividades como a diplomacia preventiva, a imposição da paz e a construção da paz (BOUTROS-GHALI, 1992).

Silva nos assevera que um dos problemas decorrentes do alargamento das tarefas relacionadas ao mandato foi o surgimento de uma lacuna entre os objetivos a serem atingidos pela missão e aquilo que, efetivamente, as operações de paz poderiam executar na prática, tanto em termos legais como materiais (SILVA, 2012).

Sob outra perspectiva, Kenkel observa que as missões de paz nesse período foram quase sempre implementadas sob os auspícios do capítulo VI da Carta das Nações Unidas, ou seja, não foram realizadas mudanças operacionais nas regras

8 As OPs de $2^{\text {a }}$ Geração também são chamadas de operações multidisciplinares, multidimensionais ou multifuncionais. 
de engajamento dos militares para atender o alargamento das atividades assumidas pelo contingente da ONU (KENKEL, 2013).

Diante dessa realidade, alguns estudiosos entendem que o sucesso dessas missões dependeria ora da boa vontade das partes em conflito, ora do peso da persuasão moral da ONU. Com isso, verificou-se que nem todas as missões nesse período lograram o êxito esperado, pelo contrário, algumas obtiveram grande fracasso e serviram de base para o emolduramento das gerações de missões futuras.

Bigatão põe ingredientes nessa discussão ao inferir que muitos analistas entenderam que a ONU atingiu resultados satisfatórios em algumas áreas, mas que não foi capaz de obter êxito na execução completa dos mandatos das missões multidisciplinares, conforme ocorrido na Namíbia, em Moçambique, em Angola e no Camboja (BIGATÃO, 2007).

Assim, Kenkel aponta o esgotamento do aparato onusiano, tanto no campo operacional quanto financeiro e institucional, fazendo com que a ONU registrasse três grandes fracassos em OPs na década de 1990: 1) o despreparo da ONU em prevenir ou limitar o genocídio de Ruanda em 1994; 2) a ineficácia da ONU na concretização de um acordo político, juntamente com as perdas militares, relativamente pesadas, na Somália; e 3) a incapacidade da ONU em proteger os civis na Bósnia, simbolizado pelo massacre de Srebrenica de 1995 (KENKEL, 2013).

Sob essa ótica de erros e acertos - ou fracassos e êxitos - é que se desenvolveram as missões de paz da $2^{\text {a }}$ Geração. Destacam-se ainda o descongelamento das ações da ONU e uma preocupação cada vez maior dessa instituição e da sociedade com a segurança do ser humano nos mais variados níveis.

Outra característica importante desse período se apoia no aumento das tarefas e atividades da ONU no país hospedeiro, sem recebimento do devido apoio estrutural, jurídico e financeiro por parte do CSNU para dar cabo dessas múltiplas demandas. O gráfico 3 apresenta as OPs de $2^{\text {a }}$ Geração: 
Gráfico 3: OPs de $2^{\mathrm{a}}$ Geração

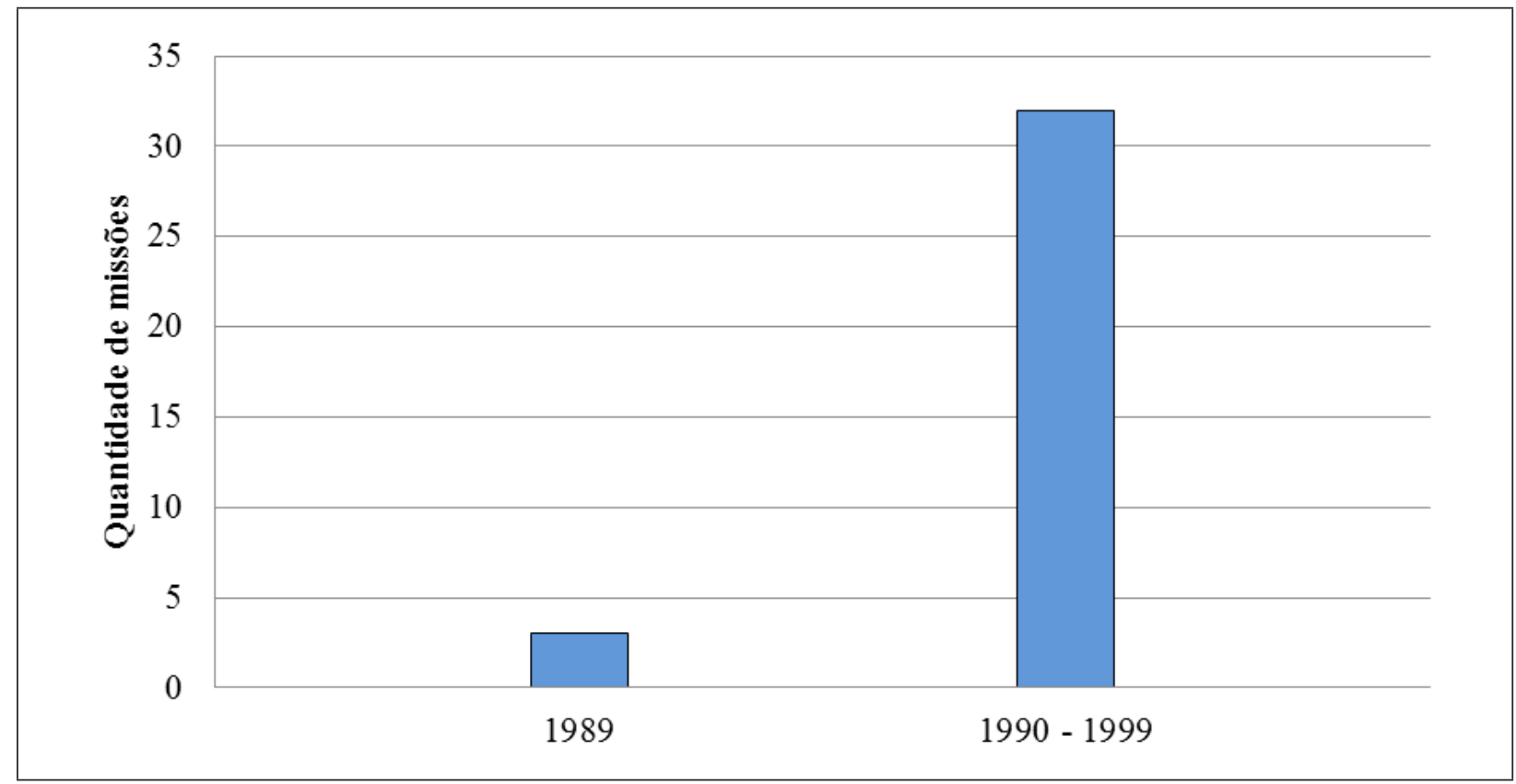

Fonte: elaboração própria, com dados do Departament of Peacekeeping Operations, 2017.

Observa-se que o número de missões de paz aumentou potencialmente, registrando 35 missões em pouco mais de 10 anos. Desse total, cabe destacar que existe uma missão de $2^{\text {a }}$ Geração ainda em curso: MINURSO (United Nations Mission for the Referendum in Western Sahara).

Dissecando ainda mais esses números, três missões da $2^{\text {a }}$ Geração tiveram início em 1989: UNAVEM I (United Nations Angola Verification Mission I), ONUCA (United Nations Observer Group in Central America) e UNTAG (United Nations Transition Assistance Group). E as outras 32 se iniciaram na década de 1990.

Ademais, ressalta-se que há três missões que se iniciaram na década de 1990 e que não foram classificadas como de $2^{\text {a }}$ Geração, pois não apresentaram características para tal: UNMIK (United Nations Interim Administration Mission in Kosovo), UNTAET (United Nations Transitional Administration in East Timor) e MONUC (United Nations Organization Mission in the Democratic Republic of the Congo).

O término da Guerra Fria e o descongelamento das ações da ONU não só aumentaram a participação da instituição no sistema internacional, como fizeram com que o Brasil acompanhasse tal tendência, à época.

Sendo assim, a participação brasileira nesse período também seguiu a tendência de alta da ONU, fazendo com que a década de 1990 presenciasse um crescimento robusto do Brasil nas OPs. O gráfico 4 apresenta a participação brasileira nas missões de paz de $2^{\text {a }}$ Geração: 


\section{Gráfico 4: Participação brasileira em OPs de $2^{a}$ Geração}

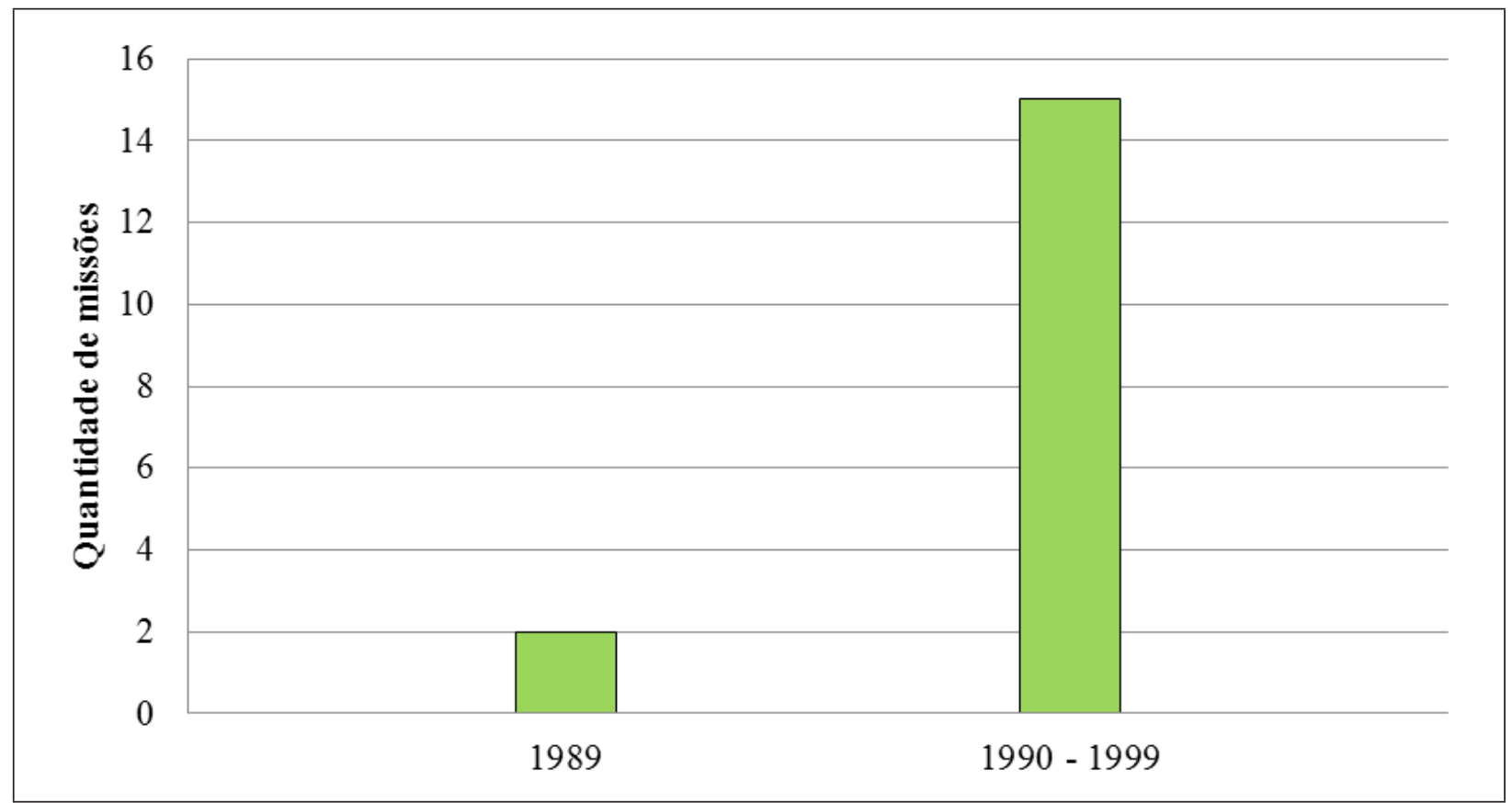

Fonte: elaboração própria, com dados do Departament of Peacekeeping Operations, 2017.

Nota-se que o Brasil participou de 17 missões num período de pouco mais de 10 anos. Ao comparar a participação brasileira nas missões de $1^{\mathrm{a}}$ e $2^{\mathrm{a}}$ gerações, verifica-se um aumento de quase 200\%. Ressalta-se que o crescimento da participação do país em missões de paz é bem superior ao crescimento obtido pela ONU em realização de missões de paz, que foi de quase 100\% . Como nas missões de $1^{\text {a }}$ Geração, o Brasil continuou em destaque. Confirmando a contribuição brasileira em termos qualitativos para as missões de paz, Castelo Branco aponta que o relatório final realizado pelo representante especial do secretário-geral da ONU, o italiano Aldo Ajello, mostra que o mandato da ONUMOZ (United Nations Operation in Mozambique) foi exitoso, destacando o papel dos capacetes azuis na aplicação do acordo geral de paz, assinado em 04 de outubro de 1992, na realização de assistência humanitária, na assistência técnica e culminando no apoio à realização das eleições livres no país (CASTELO BRANCO, 2003).

Colares acrescenta elementos adicionais ao tema, lembrando que a ONUMOZ foi importante para o Brasil, pois foi nessa missão que o país voltou a empregar suas tropas em OPs, inclusive designando um brasileiro para o cargo de Force Comander na ONUMOZ, função exercida pelo general Lélio Rodrigues da Silva entre fevereiro de 1993 e fevereiro de 1994 (COLARES, 2014). Para que se tenha uma ideia mais pormenorizada da participação brasileira nas OPs de $2^{\text {a }}$ Geração, apresenta-se o quadro 2: 
Quadro 2: Participação brasileira em OPs de $2^{a}$ Geração

\begin{tabular}{|c|c|c|c|c|c|}
\hline Missão & Localização & Militares & Policiais & Civis & Período \\
\hline UNAVEM I & Angola & 24 & - & - & $1989-1991$ \\
\hline ONUCA & América Central & 47 & - & - & $1989-1992$ \\
\hline UNAVEM II & Angola & 104 & 50 & 14 & $1991-1995$ \\
\hline ONUSAL $^{10}$ & El Salvador & 54 & 17 & - & $1991-1995$ \\
\hline MINURSO & Saara Ocidental & 92 & - & - & 1991 - dias atuais \\
\hline ONUMOZ & Moçambique & 225 & 65 & 16 & $1992-1994$ \\
\hline UNTAC 11 & Camboja & - & - & 19 & $1992-1993$ \\
\hline UNOMSA $^{12}$ & África do Sul & - & - & 12 & $1992-1994$ \\
\hline UNPROFOR ${ }^{13}$ & Ex-Iugoslávia & 82 & 16 & - & $1992-1995$ \\
\hline UNOMUR14 & Ruanda/Uganda & 23 & - & - & $1993-1994$ \\
\hline UNOMIL 15 & Libéria & 3 & - & - & $1993-1997$ \\
\hline UNCRO16 & Croácia & 14 & 2 & - & $1995-1996$ \\
\hline UNAVEM III'17 & Angola & 4.174 & 48 & - & $1995-1997$ \\
\hline UNPREDEP18 & Macedônia & 7 & - & - & $1995-1999$ \\
\hline UNTAES $^{19}$ & Eslovênia/Oriental & 12 & 2 & - & $1996-1998$ \\
\hline UNMOP20 & Pevlalka & 6 & - & - & $1996-2002$ \\
\hline MINUGUA ${ }^{21}$ & Guatemala & 18 & 13 & - & 1997 \\
\hline MONUA $^{22}$ & Angola & 15 & 33 & - & $1997-1999$ \\
\hline \multicolumn{2}{|c|}{ TOTAL } & 4.920 & 286 & 61 & 5267 \\
\hline
\end{tabular}

Fonte: elaboração própria, com dados do Departament of Peacekeeping Operations, 2017.

Percebe-se a maior participação de policiais e civis brasileiros nas missões onusianas, confirmando a preocupação da ONU com a paz duradoura, com foco na gestão do conflito e não mais na simples resolução do mesmo. Com um

9 UNAVEM II - United Nations Angola Verification Mission II.

10 ONUSAL - United Nations Observer Mission in El Salvador.

11 UNTAC - United Nations Transitional Authority in Cambodia.

12 UNOMSA - United Nations Observer Mission in South Africa.

13 UNPROFOR - United Nations Protection Force.

14 UNOMUR - United Nations Observer Mission Uganda-Rwanda.

15 UNOMIL - United Nations Observer Mission in Liberia.

16 UNCRO - United Nations Confidence Restoration Operation in Croatia.

17 UNAVEM III - United Nations Angola Verification Mission III.

18 UNPREDEP - United Nations Preventive Deployment Force.

19 UNTAES - United Nations Transitional Administration for Eastern Slavonia, Baranja and Western Sirmium.

20 UNMOP - United Nations Mission of Observers in Prevlaka.

21 MINUGUA - United Nations Verification Mission in Guatemala. Período de janeiro à maio de 1997.

22 MONUA - United Nations Observer Mission in Angola. 
efetivo de 286 policiais e de 61 civis brasileiros, o país seguiu essa tendência e se adequou ao alargamento do rol de tarefas requeridas pela ONU para a restauração da paz nos locais em conflito. Verifica-se, também, o papel de destaque exercido pelo Brasil na UNAVEM III, ocorrida em Angola, envolvendo 4.174 militares e 48 policiais brasileiros entre 1995 e 1997. A designação do general Lélio Rodrigues da Silva como Force Comander na ONUMOZ descortina outros tipos de contribuição brasileira às OPs, as chamadas Token Troop Contributions.

A $2^{\text {a }}$ Geração das OPs proporcionou ensinamentos para as futuras gerações, seguindo uma tendência verificada já na $1^{\text {a }}$ Geração. Nesse contexto, Kenkel nos assevera que cada uma das missões ocorridas nesse período foi capaz de gerar ensinamentos nos princípios da manutenção da paz, levando ao surgimento de uma $3^{\text {a }}$ Geração de operações de paz (KENKEL, 2013). Sendo assim, pode-se inferir que as missões de $3^{\text {a }}$ Geração surgem da evolução natural da $2^{\text {a }}$ Geração, refletindo novamente o ambiente internacional de sua época e seus reflexos para a evolução das OPs.

\section{A $3^{\mathrm{a}}$ Geração das operações de paz}

Os fracassos da ONU em Ruanda, na Somália e na Bósnia chamaram a atenção da comunidade internacional, fazendo com que a mesma se debruçasse sobre o tema com o objetivo de encontrar respostas para o ocorrido. Bigatão assinala que o fracasso em tais operações fez com que o Secretário-Geral da ONU, Kofi Annan, solicitasse a um grupo de estudiosos internacionais uma revisão dos temas relativos às missões de paz, cujos resultados foram concentrados num documento chamado de Relatório Brahimi (BIGATÃO, 2007).

Esse documento foi o motor necessário para que a $3^{\text {a }}$ Geração ganhasse forma e contorno e se distinguisse da $2^{\text {a }}$ Geração das operações de paz. Nesse sentido, o Relatório Brahimi se tornou um documento fundamental para a compreensão da natureza e do funcionamento das OPs da atualidade. Williams destaca o papel exercido pelo Relatório Brahimi ao assinalar que, após os fracassos da ONU na Somália e em Serra Leoa, as missões de paz teriam que ser suficientemente fortes para impedir que os oponentes atacassem os integrantes da ONU, além de garantir a segurança dos civis na região (WILLIAMS, 2010).

Foi nesse contexto que surgiram as OPs de $3^{\mathrm{a}}$ Geração, as quais tiveram início no final da década de 1990 e se estendem até os dias atuais. A diferença mais flagrante das OPs de $3^{\text {a }}$ Geração para as missões de $2^{\text {a }}$ Geração é a autorização 
do uso da força pelas tropas da ONU. Nessa linha de pensamento, Osman destaca que essas missões foram caracterizadas pelo aumento do uso da força para atingir os objetivos propostos pelo mandato da ONU (OSMAN, 2002).

Aguilar também assevera que os mandatos da organização supranacional passaram a utilizar maior uso da força pelo componente militar e insere ingredientes ao inferir que as OPs de $3^{\text {a }}$ Geração demandavam um emprego cada vez maior do componente civil da ONU na região do conflito (AGUILAR, 2015). O gráfico 5 apresenta o número total de OPs de $3^{\text {a }}$ Geração:

\section{Gráfico 5: OPs de $3^{\mathrm{a}}$ Geração}

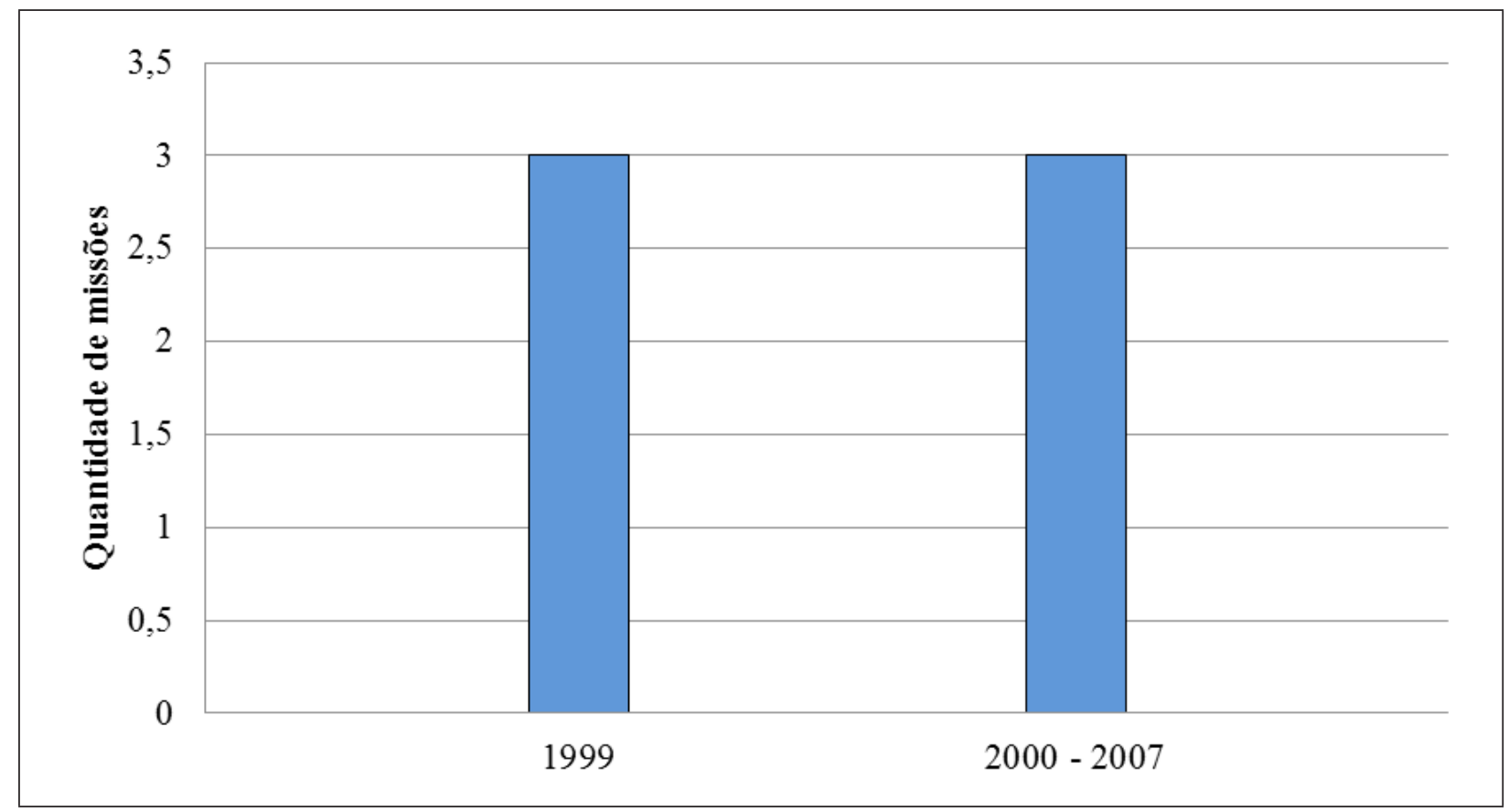

Fonte: elaboração própria, com dados do Departament of Peacekeeping Operations, 2017.

De acordo com o gráfico, há seis missões de paz de $3^{\text {a }}$ Geração. Das seis, uma não se iniciou nesse período: a UNIFIL, que teve início em 1978 e que, até 2006, era uma missão de $1^{\text {a }}$ Geração - com a resolução $n^{0}$ 1701, de 2006, do CSNU, essa missão passou a integrar a $3^{\text {a }}$ Geração de operações de paz, pelo mandato mais robusto a que foi submetida.

As demais missões são as seguintes: 1) UNMIK (United Nations Interim Administration Mission in Kosovo), 2) UNTAET (United Nations Transitional Administration in East Timor), 3) MONUC (United Nations Organization Mission in the Democratic Republic of the Congo), 4) UNMISET (United Nations Mission of Support in East Timor) e 5) MINURCAT (United Nations Mission in the Central African Republic and Chad). 
Gráfico 6: Participação brasileira em OPs de $3^{\text {a }}$ Geração

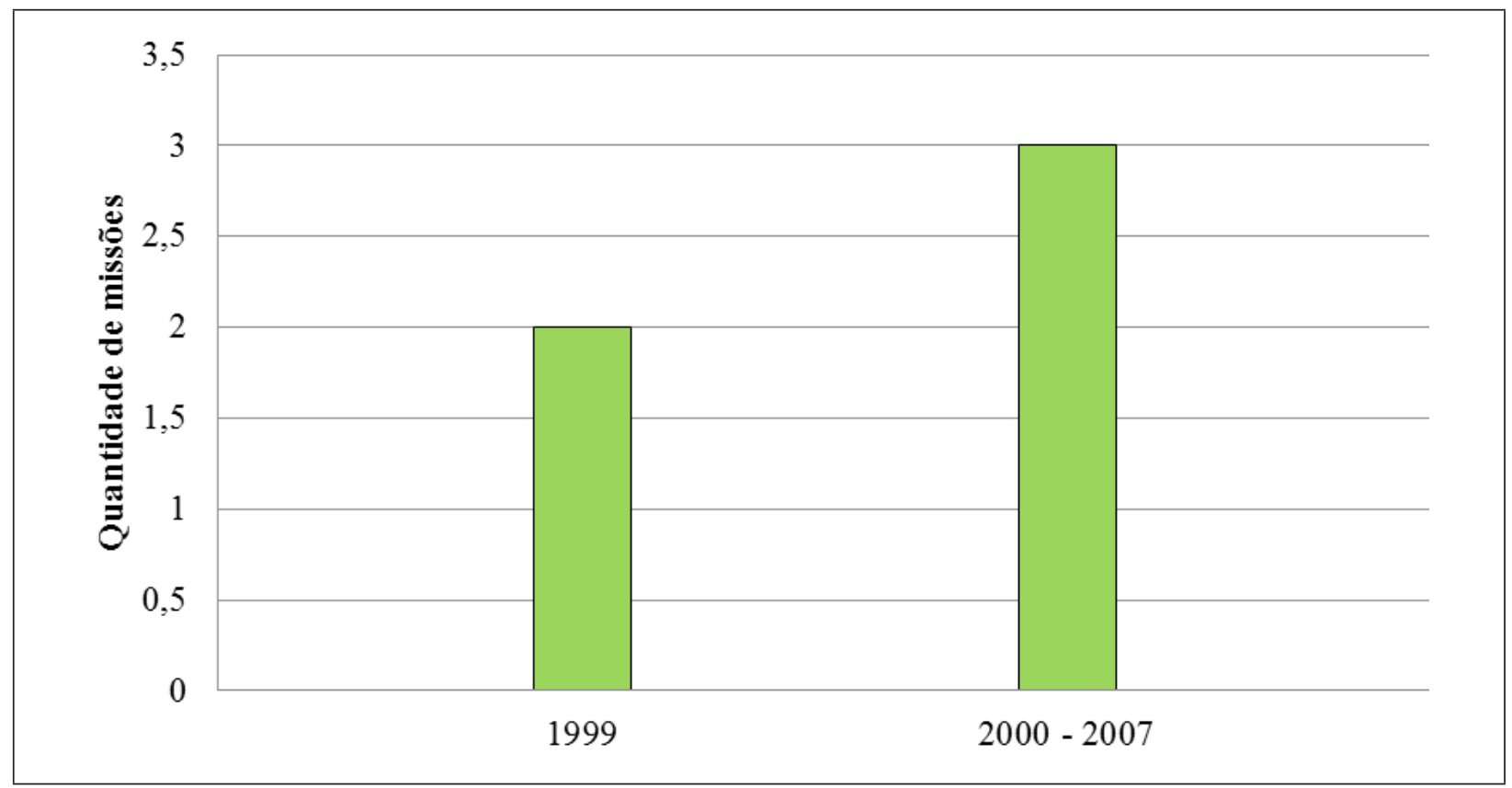

Fonte: elaboração própria, com dados do Departament of Peacekeeping Operations, 2017.

Complementando as informações do gráfico, o quadro 3 detalha a participação brasileira nas OPs de $3^{\text {a }}$ Geração:

Quadro 3: Participação brasileira em OPs de $3^{\text {a }}$ Geração

\begin{tabular}{|c|c|c|c|c|c|}
\hline Missão & Localização & Militares & Policiais & Civis & Período \\
\hline UNTAET & Timor Leste & 174 & 25 & - & $1999-2002$ \\
UNMIK & Kosovo & - & 15 & - & $1999-$ dias atuais \\
UNMISET & Timor Leste & 274 & 17 & 19 & $2002-2005$ \\
& África Central e & 06 & - & - & $2007-2010$ \\
MINURCAT & República do Chade & 1496 & - & - & $1978-$ dias atuais \\
UNIFIL & Líbano & $\mathbf{1 9 5 0}$ & $\mathbf{5 7}$ & $\mathbf{1 9}$ & $\mathbf{2 0 2 6}$ \\
\hline \multicolumn{2}{|c|}{ TOTAL (brasileiros) }
\end{tabular}

Fonte: elaboração própria, com dados do Departament of Peacekeeping Operations, 2017.

O quadro 4 evidencia a importância da UNIFIL para o Brasil, pois contou com a participação de 1496 militares brasileiros, sendo a maioria pertencente à Marinha. E o destaque não reside somente nesses números. Abdenur ressalta a liderança exercida pela Marinha do Brasil na força-tarefa marítima no Líbano. Esse fato fez com que o Brasil se tornasse o primeiro país não membro da OTAN a comandar uma força-tarefa marítima em operações de paz sob a égide da ONU. Assim, nos dias atuais, o Brasil comanda uma esquadra no Líbano composta por 
sete navios: dois de Bangladesh, um da Grécia, um da Indonésia, um da Alemanha, um da Turquia e a nau capitânia brasileira, com substituição a cada seis meses do efetivo empregado pelo Brasil na UNIFIL (ABDENUR, 2016).

Já Penna ressalta a contribuição brasileira na UNTAET, onde o brasileiro Sérgio Vieira de Mello foi nomeado, pela resolução 1272 da ONU, para exercer a autoridade transitória no Timor Leste, com domínio sobre os poderes executivo, legislativo e de segurança do país (PENNA, 2009). Seitenfus também enaltece a contribuição brasileira no Timor Leste, reforçando que a contribuição brasileira englobou vários campos do poder: 1) a presença de militares no campo tático, 2) a liderança política brasileira exercida por Sérgio Vieira de Mello, no contexto da UNTAET (Administração Transitória das Nações Unidas para o Timor Leste) e 3) a contribuição do Brasil no campo social, envolvendo as áreas da saúde, da educação, da agricultura e da justiça, confirmando o caráter multidimensional e o sucesso alcançado (SEITENFUS, 2008).

Sendo assim, pode-se compreender que a combinação do uso elevado da força, caracterizado pela inclusão de uma força-tarefa marítima no Líbano, bem como o aumento nas tarefas civis nos mandatos transitórios, emolduraram a base necessária para o surgimento da $4^{a}$ Geração das operações de paz.

\section{A $4^{\mathrm{a}}$ Geração das operações de paz}

Para Bellamy, a $4^{\text {a }}$ Geração das OPs consiste na consolidação robusta das OPs de $3^{\text {a }}$ Geração, ao combinar a permissão para usar a força com a autorização para exercer tarefas civis complexas, proporcionando condições satisfatórias para a efetiva reconstrução do país hospedeiro (BELLAMY et al., 2010). Sendo assim, conclui-se que a $4^{\text {a }}$ Geração das OPs nasceu, praticamente, do aperfeiçoamento da geração anterior.

E, nesse aspecto, destaca-se o papel do Brasil nessa geração de OPs. Motivada por algumas intervenções externas que agravaram ainda mais a sensação de insegurança em países hospedeiros, a presidente Dilma Rousseff fez uma proposta, em 2011, na sede da ONU, provocando os países a refletirem e discutirem sobre o conceito de responsabilidade "ao" proteger, fruto da evolução do conceito anterior existente que era de responsabilidade "de" proteger.

Barnett relata que a origem doutrinária da $4^{\text {a }}$ Geração das OPs teve sua semente plantada em 1994, quando o secretário-geral da ONU, Boutros Boutros-Ghali, se 
pronunciou publicamente definindo o conceito de peacebuilding ${ }^{23}$ pós-conflito em um suplemento da agenda para a paz (BARNETT; ZURCHER, 2009). Na visão do então secretário-geral da ONU, a construção ou reconstrução de determinadas estruturas fortaleceriam o processo de paz no país hospedeiro e evitariam uma recaída durante tal processo. Assim, a $4^{\text {a }}$ Geração passou a ser conhecida como OPs de construção da paz.

Richmond entende que essas missões se caracterizam, na sua essência, em prevenir formas de violência direta ou indireta por meio da reconstrução ou construção de determinadas estruturas no país hospedeiro, as quais fortalecerão o processo de paz (RICHMOND, 2004). Mas entender as OPs de $4^{\text {a }}$ Geração não é tarefa simples. Para Barnett, há três dimensões de peacebuilding pós-conflito: 1) criação de estabilidade; 2 ) restauração de instituições estatais; e 3) direcionamento das dimensões socioeconômicas do conflito (BARNETT; ZURCHER, 2009).

Christie assevera que essas missões marcaram uma mudança significativa nas metas de intervenção internacional, pois as mesmas preconizam a reestruturação dos sistemas político e econômico do país hospedeiro, de tal forma que as mesmas promovam a satisfação equitativa e sustentável das necessidades humanas (CHRISTIE, 2006). Diante desse alargado rol de tarefas e definições, será mostrado o gráfico 7 , com o número total de OPs de $4^{\text {a }}$ Geração:

\section{Gráfico 7: OPs de $4^{\mathrm{a}}$ Geração}

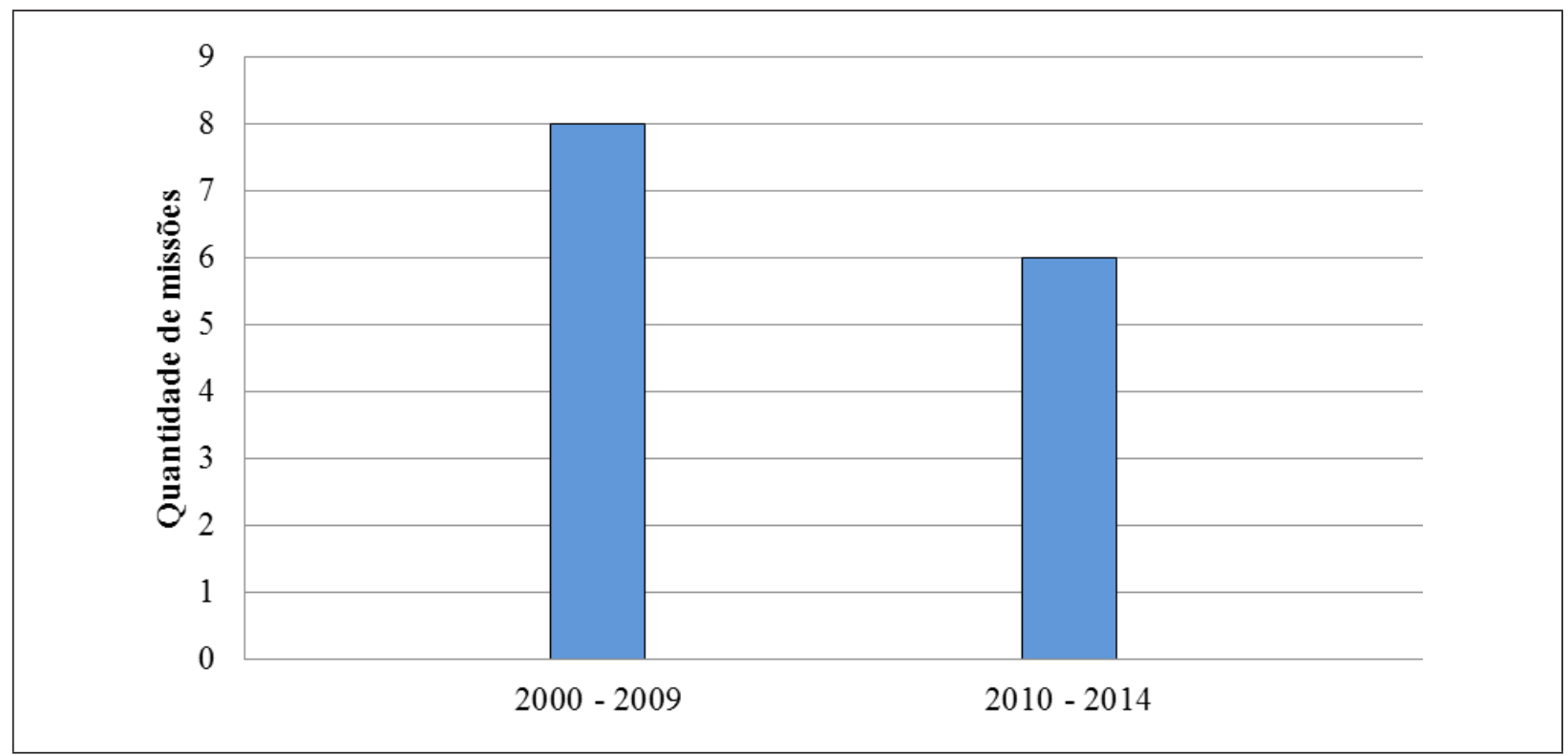

Fonte: elaboração própria, com dados do Departament of Peacekeeping Operations, 2017.

23 Peacebuilding - conceito definido pela Agenda Para a Paz, em 1992: Tradução própria — "uma ação para identificar e suportar estruturas que tendem a fortalecer e solidificar a ordem de paz para evitar uma recaída no conflito" (UN, 1992). Do original em inglês - "an action to identify and support structures whichtend to strenghten and solidify peacein order to avoid a relapse into conflict" (UN, 1992). 
O gráfico revela que há 14 missões na $4^{\text {a }}$ Geração das operações de paz. Dessas, 6 já terminaram suas atividades e 8 ainda estão em andamento. No que concerne ao papel do Brasil nesse período, o gráfico a seguir apresenta a participação brasileira:

Gráfico 8: Participação brasileira em OPs de $4^{\text {a }}$ Geração

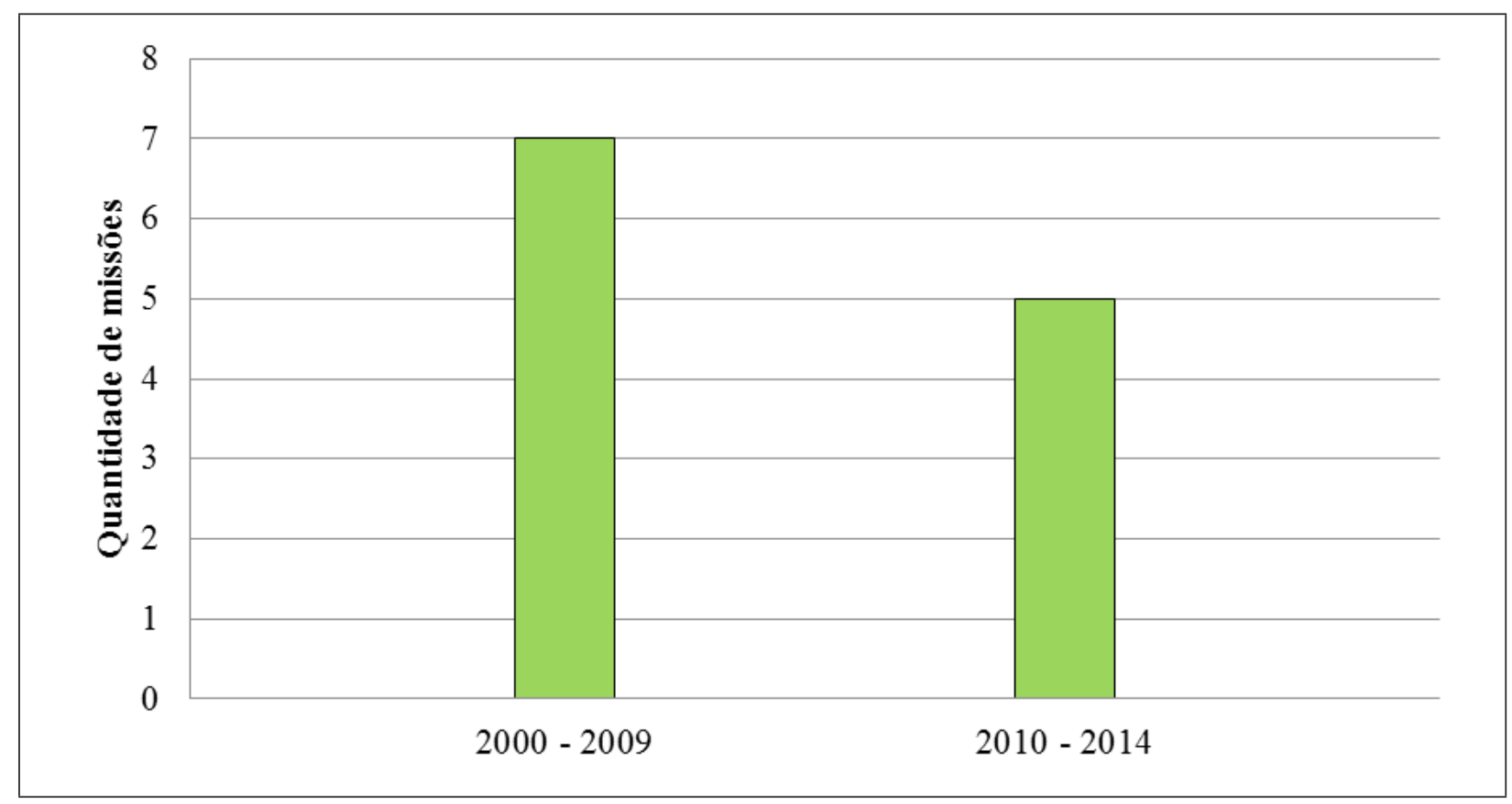

Fonte: elaboração própria, com dados do Departament of Peacekeeping Operations, 2017.

Registra-se a participação do país em 12 OPs de $4^{\mathrm{a}}$ Geração, o que reflete um expressivo aumento em comparação com a participação brasileira na geração anterior. Porém, não foi só quantitativa a contribuição brasileira nesse período.

O papel do Brasil na crise haitiana não ficou limitado somente ao envio de forças militares e no protagonismo do comando da MINUSTAH. Segundo Nasser, o país destinou recursos para a reconstrução do Haiti e ajudou na realização de eleições presidenciais e outras tarefas adicionais, evidenciando a preocupação brasileira na reorganização das instituições democráticas haitianas (NASSER, 2012). Além disso, a MINUSTAH demonstrou a excelente cooperação e harmonia das forças armadas sul-americanas em operações militares combinadas. Esse trabalho em conjunto possibilitou que a expressão militar da missão pudesse ajudar o Brasil no projeto político brasileiro de melhor conformar sua área de influência e consolidar sua liderança regional (PACHECO; MIGON, 2013). Para que se tenha uma ideia mais detalhada do papel do Brasil na $4^{\text {a }}$ Geração das OPs, será mostrado o quadro 4: 


\section{Quadro 4: Participação brasileira em OPs de $4^{\mathrm{a}}$ Geração}

\begin{tabular}{|c|c|c|c|c|}
\hline Missão & Localização & Militares & Policiais & Período \\
\hline UNMEE 24 & Etiópia e Eritréia & 12 & - & $2000-2008$ \\
\hline UNMIL $^{25}$ & Libéria & 38 & - & 2003 - dias atuais \\
\hline $\mathrm{UNOCI}^{26}$ & Costa do Marfim & 73 & - & 2004 - dias atuais \\
\hline MINUSTAH & Haiti & 18.422 & 96 & 2004 - dias atuais \\
\hline UNMIS27 & Sudão & 141 & 16 & $2005-2011$ \\
\hline UNMIT $^{28}$ & Timor Leste & 30 & 61 & $2005-2012$ \\
\hline UNMIN29 & Nepal & 33 & - & $2007-2011$ \\
\hline MONUSCO ${ }^{30}$ & Congo & 13 & - & 2010 - dias atuais \\
\hline UNISFA 31 & Abyel & 15 & - & 2011 - dias atuais \\
\hline UNMISS $^{32}$ & Sudão do Sul & 53 & 16 & 2011 - dias atuais \\
\hline UNSMIS 33 & Síria & 1 & - & $2012-2012$ \\
\hline MINUSCA 34 & África Central & 20 & - & 2014 - dias atuais \\
\hline \multicolumn{2}{|c|}{ TOTAL (brasileiros) } & 16.859 & 169 & 17.028 \\
\hline
\end{tabular}

Fonte: elaboração própria, com dados do Departament of Peacekeeping Operations, 2017.

Nota-se que o Haiti registra o maior contingente brasileiro em missões de paz de toda história. Contando com 18.422 militares e 96 policiais, a MINUSTAH é a maior contribuição brasileira em operações de paz. Aguilar relaciona o protagonismo brasileiro no Haiti à ação da diplomacia solidária brasileira, na qual o Brasil soube estimular a atuação de outros Estados em território haitiano, todos movidos pelo "dever de consciência” (AGUILAR, 2015).

Outra participação brasileira que merece destaque é a acontecida no Congo. A designação do general Santos Cruz para chefiar a MONUSCO foi feita diretamente pelo secretário-geral da ONU, Ban Ki-moon, numa tentativa de superar os desafios de desmoralização da instituição no Congo (DE SOUZA, 2015).

\footnotetext{
24 UNMEE - United Nations Mission in Ethiopia and Eritrea.

25 UNMIL - United Nations Mission in Liberia.

26 UNOCI - United Nations Operation in Côte d'Ivorie.

27 UNMIS - United Nations Mission in the Sudan.

28 UNMIT - United Nations Integrated Mission in Timor-Leste.

29 UNMIN - United Nations Mission in Nepal.

30 MONUSCO - United Nations Organization Stabilization Mission in the Democratic Republic of the Congo.

31 UNISFA - United Nations Interim Security Force for Abyei.

32 UNMISS - United Nations Mission in the Republic of South Sudan.

33 UNSMIS - United Nations Supervision Mission in Syria.

34 MINUSCA - United Nations Multidimensional Integrated Stabilization Mission in the Central African Republic.
} 
Assim como na MINUSTAH, De Souza salienta ainda que o general brasileiro também se destacou na MONUSCO, pois o mesmo conseguiu neutralizar os principais grupos armados e garantiu maior proteção aos civis na região do conflito (DE SOUZA, 2015). Pelo que foi exposto, conclui-se que o Brasil prestou importante colaboração para as OPs de $4^{\text {a }}$ Geração, tanto em termos qualitativos como quantitativos.

\section{Conclusões}

Inicia-se esta seção relembrando a evolução das missões de paz. Para tanto, será apresentada a Figura 1, que resume o processo de evolução das OPs da ONU:

Figura 1: As quatro gerações de OPs da ONU

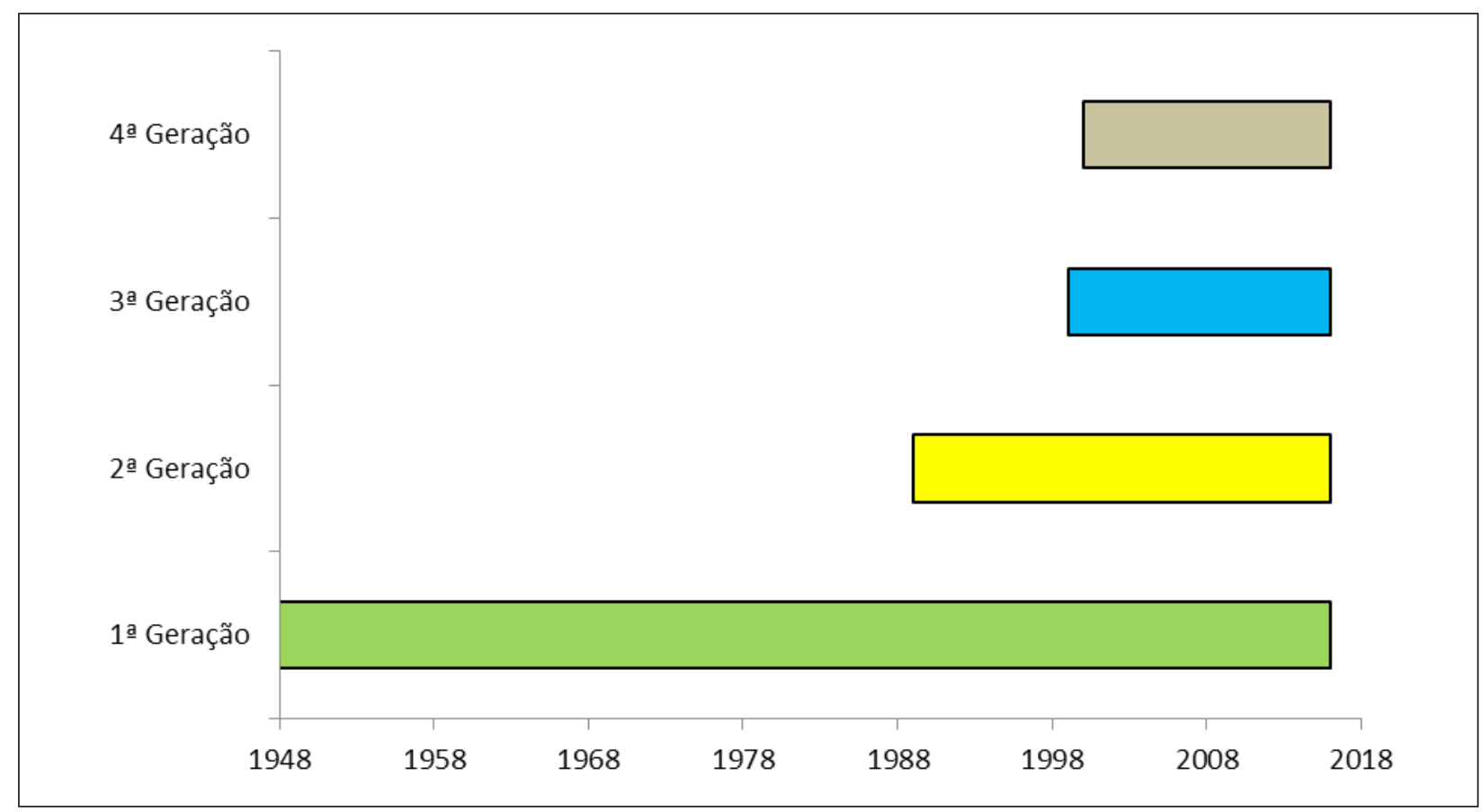

Fonte: elaboração própria, com dados do Departament of Peacekeeping Operations, 2017.

A $1^{\text {a }}$ Geração se iniciou com a UNTSO em 1948 e ainda permanece atualmente com quatro missões em curso: 1) UNTSO, 2) UNMOGIP, 3) UNFICYP e 4) UNDOF. O detalhe fica por conta da UNIFIL, que em 1978 atuava sob o escopo de $1^{\text {a }}$ Geração e, com o mandato alterado em 2007, passou a integrar a $3^{\text {a }}$ Geração das OPs.

Passando para a $2^{\text {a }}$ Geração, verifica-se que ela teve início com a UNAVEM I em 1989, registrando um total de 35 OPs em todo o seu histórico. Da mesma forma que a $1^{\text {a }}$ Geração, a $2^{\text {a }}$ Geração está presente nos dias atuais e conta com apenas uma operação de paz ocorrendo nos dias de hoje: MINURSO. 


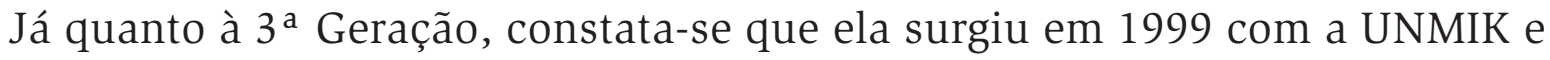
permanece nos dias atuais também, registrando seis OPs em toda a sua história. O aspecto inovador nessa geração de OPs ficou por conta da UNIFIL, missão de paz que teve início em 1978, estando enquadrada na $1^{\text {a }}$ Geração de operações de paz até 2006. Porém, a resolução ${ }^{\circ} 1701$, de 2006, do CSNU, mudou o mandato da UNIFIL, alargando o rol de atribuições e tarefas da mesma, fazendo com que essa passasse a ser caracterizada como uma missão de paz típica de $3^{\text {a }}$ Geração. Atualmente, a $3^{a}$ Geração de OPs conta com apenas duas missões em curso: 1) UNMIK e 2) UNIFIL.

A $4^{\text {a }}$ Geração se iniciou no ano de 2000 com a UNMEE e ainda está presente nos dias atuais, assinalando 14 missões em seu histórico. Das 14, seis já se encerraram e 8 continuam suas atividades: 1) UNMIL, 2) UNOCI, 3) MINUSTAH, 4) MONUSCO, 5) UNISFA, 6) UNMISS, 7) MINUSCA e 8) MINUSMA (United Nations Multidimensional Integrated Stabilization Mission in the Central African Republic).

Sendo assim, conclui-se que atualmente a ONU desenvolve 16 OPs ao redor do mundo, assim classificadas: 4 missões de $1^{a}$ Geração, 1 missão de $2^{a}$ Geração, 2 missões de $3^{a}$ Geração, 8 missões de $4^{a}$ Geração e 1 missão que pode vir a ser o início da $5^{a}$ Geração de OPs (UNAMID).

Com relação à contribuição brasileira para as OPs, ficou constatado, ao longo do trabalho, que o país se engajou nesse tema e deu significativa contribuição no decorrer dos anos. Para que se possa ter uma real compreensão disso, o gráfico 9 faz uma comparação da participação brasileira nas gerações de OPs:

\section{Gráfico 9: Participação brasileira nas gerações de OPs}

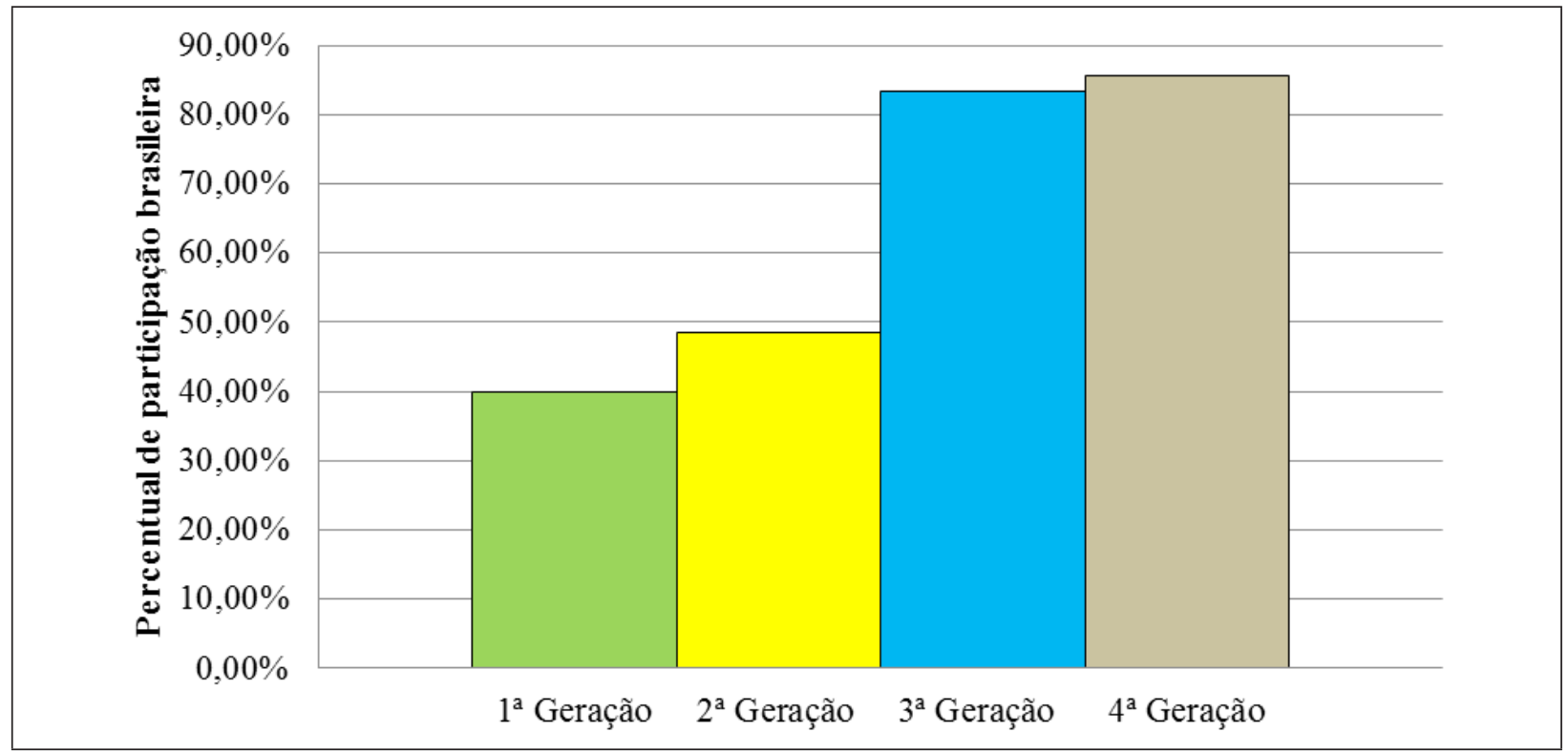

Fonte: elaboração própria, com dados do Departament of Peacekeeping Operations, 2017. 
Analisando o gráfico 9, pode-se inferir que o país aumentou gradativamente a sua participação nas missões conduzidas pela ONU, iniciando com uma atuação de $40 \%$ nas OPs de $1^{a}$ Geração, e passando para uma participação de 48,57\% nas OPs de $2^{a}$ Geração. Confirmando a trajetória ascendente da atuação brasileira em missões de paz, o país alcança 83,33\% nas OPs de $3^{a}$ Geração e chega atualmente com 85,71\% de participação nas OPs de $4^{a}$ Geração.

A trajetória ascendente da participação brasileira em OPs ao longo dos anos demonstra maior envolvimento do governo brasileiro com as missões onusianas, bem como denota um crescimento da inserção do país em assuntos de segurança e defesa no cenário internacional.

Além desses números, cabe destacar o papel do país na evolução doutrinária das missões de paz e em algumas Token Troop Contributions, citadas na sequência. No âmbito da UNEF I, o destaque fica por conta do pioneirismo brasileiro, por ter sido o primeiro país a enviar um contingente armado em OPs. A ONUMOZ representa o retorno do Brasil no envio de tropas em missões onusianas, tendo o singular destaque do general brasileiro Lélio Rodrigues da Silva, que exerceu por algum tempo o cargo de Force Comander na missão. Na UNAVEM III, sublinham-se o efetivo expressivo e o comando militar da operação de paz. Na UNTAET, ressalta-se a liderança brasileira exercida no nível político por Sérgio Vieira de Melo. Na MONUSCO, evidencia-se a liderança do contingente militar exercida pelo general Santos Cruz e o respectivo sucesso alcançado. Na UNIFIL, cumpre ressaltar o feito alcançado pelo Brasil ao se tornar o primeiro país fora da OTAN a comandar uma força-tarefa marítima em OPs. E na MINUSTAH, os destaques ficam por conta de o comando militar (Force Comander) ter permanecido exclusivamente com o Brasil em todo o período de duração e do papel multidimensional exercido pelo país em vários campos do poder.

Por fim, cabe ressaltar que a participação ativa do país em questões relativas à segurança e defesa internacional, com seus nacionais integrando diversas missões de paz e, sobretudo, com soluções brasileiras inéditas para os problemas que surgem ou surgiram no decorrer das missões, evidenciam o papel protagonista do Brasil na contribuição à evolução doutrinária das OPs sob a égide da ONU.

\section{Referências}

ABDENUR, Adriana Erthal. Rising Powers in Stormy Seas: Brazil and the UNIFIL Maritime Task Force. International Peacekeeping. Vol. 23, nº 3, 2016, p. 389-415. Disponível em: http://www.tandfonline.com/toc/finp20/23/3?nav = tocList. Acesso em: 13 abr. 2017. 
AGUILAR, Sérgio Luiz Cruz. Brasil em Missões de Paz. São Paulo: Editora Usina do Livro, 2005.

AGUILAR, Sérgio Luiz Cruz. A Participação do Brasil nas Operações de Paz: passado, presente e futuro. Brasiliana - Journal for Brazilian Studies. Vol. 3, $\mathrm{n}^{\mathrm{o}}$ 2, 2015, p. 113-141. Disponível em: http://www.ojs.statsbiblioteket.dk/index.php/bras/issue/ view/2733/showToc. Acesso em: 10 mar. 2017.

BARNETT, Michael; ZURCHER, Cristoph. The Peacebuiler's Contract: How External Statebuilding Reinforces Weak Statehood. In: PARIS, Roland; SISK, Thimothy (Orgs). The Dilemas of Statebuilding: Confronting the Contradictions of Postwar Peace Operations. Abingdton, London: Routledge, 2009, p. 23-52.

BELLAMY, Alex J. The 'Next Stage' in Peace Operations Theory? International Peacekeeping. Vol. 11, $\mathrm{n}^{\mathrm{o}}$ 1, 2004, p. 17-38. Disponível em: http://www.tandfonline.com/toc/ finp20/11/1?nav = tocList. Acesso em: 13 fev. 2017.

BELlamY, Alex J; WILliams, Paul D. The West and Contemporany Peace Operations. Journal of Peace Research. Vol. 46, n 1, 2009, p. 39-57. Disponível em: http://www. journals.sageup. com/toc/jpra/46/1. Acesso em: 11 dez. 2016.

BELLAMY, Alex J; WILLIAMS, Paul D; GRIFFIN, Stuart. Understanding Peacekeeping. $2^{\text {a }}$ edição, Malden: Polity Press, 2010.

BIGATÃo, Juliana de Paula. As Operações de Manutenção da Paz das Nações Unidas no pós-Guerra Fria: o desafio dos conflitos armados intra-estatais. In: I Encontro Nacional da Associação Brasileira de Assuntos de Defesa-ABED, 2007, São Carlos, SP. Anais Eletrônicos. Disponível em: http://www.abedef.org/conteudo/view?ID_ CONTEUDO = 74. Acesso em: 11 fev. 2017.

BOUTROS-GHALI, Boutros. An Agenda for Peace: Preventive Diplomacy, Peacemaking and Peace-keeping. (Report oh the secretary-general pursuant to the statement adopted by the summit meeting of the Security Council on 31 january 1992). 1992. Disponível em: http://www.un.org/docs/SG/agpeace.html. Acesso em: 15 mar. 2017.

BOUTROS-GHALI, Boutros. UN Peace-Keeping in a New Era: A New Chance for Peace. The World Today. Vol. 49, nº 4, 1993, p. 66-69. Disponível em: http://www.jstor.org/stab le $/ 40396494$ ? Search $=$ yes \&resultItemClick $=$ true\&searchText $=$ Boutros-Ghali\&searchU ri $=\%$ 2Faction \% 2FdoBasicSearch \% 3Fquery \% 3Dboutros-Ghali \% 26amp \% 3Bsd \% 3D \% 26amp \% 38page \% 3D2 \% 26amp \% 3Bed \% 3D \% 26amp \% 3bfilter \% 3Djid \% 253A10.230 $7 \% 252 \mathrm{Fj} 500000631 \&$ seq = 1\#page_scan_tab_contents. Acesso em: 10 fev. 2017.

BRAGA, Carlos Chagas Vianna. Uso da Força nas Operações de Paz: Solução ou Problema? In: KENKEL, Kai Michael; MORAES, Rodrigo Fracalossi de. O Brasil e as Operações de Paz em um mundo globalizado. Entre a tradição e a inovação. Brasília: IPEA, 2012. Cap. 2, p. 49-68. 
CASTELO BRANCO, Luís. As missões da ONU na África Austral: Sucessos e Fracassos. Nação

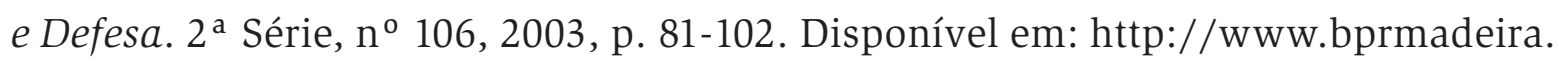
org/imagens/documentos/File/bprdigital/revistas/nacaodefesa/PP43_2003.pdf. Acesso em: 13 mar. 2017.

CEPIK, Marco Aurélio Chaves; KUELE, Giovanna Marques. Inteligência em operações de Paz da ONU (1945-2000). Revista Carta Internacional, Vol. 10, nº 1, 2015, p. 21-38. Disponível em: http://www.cartainternacional.abri.org.br/Carta/article/view/178. Acesso em: 15 abr. 2017.

CHRISTIE, Daniel J. What is Peace Psychology the Psychology of? Journal of Social Issues, Vol. 62, nº 1, 2006, p. 1-17. Disponível em: http://www.onlinelibrary.wiley. com Acesso em: 15 dez. 2016.

COLARES, Luciano da S. O Brasil e as Operações de Paz da ONU: projeção de poder pela via multilateral. In: ARTURI, Carlos S. Políticas de Defesa, Inteligência e Segurança. Porto Alegre: Editora da UFRGS, 2014, p. 147-167.

COLEMAN, Katharina P. Token Troop Contributions to United Nations Peacekeeping Operations. In: BELLAMY, Alex J; WILliAMS, Paul D. Providing Peacekeepers: The Politics, Challenges, and Future of United Nations Contributions. Oxford: Oxford University Press, 2013, p. 47-70.

CRESWELL, John W. Projeto de Pesquisa: métodos qualitativo, quantitativo e misto. $3^{\mathrm{a}}$ Edição, Porto Alegre: Artmed, 2010.

DE SOUZA, Graziene Carneiro. MONUSCO: a atuação brasileira em operações de paz robustas. Brasiliana - Journal for Brazilian Studies. Vol. 3, no 2, 2015, p. 169-196. Disponível em: http://www.ojs.statsbiblioteket.dk/index.php/bras/issue/view/2733/ show Toc. Acesso em: 10 mar. 2017.

DIEHL, Paul. Peace Operations. Malden: Polity Press, 2008.

ELLIS, Charles Howard. The origin, structure \& working of the League of nations. London: G. Allen \& Unwin, 1928.

FONTOURA, Paulo Roberto Campos Tarisse da. O Brasil e as Operações de Paz das Nações Unidas. Brasília: IRBr/FUNAG, 1999.

FONTOURA, Paulo Roberto Campos Tarisse da. O Brasil e as Operações de Manutenção da Paz das Nações Unidas. Brasília: IRBr/FUNAG, 2005.

HILLEN, Jhon. Blue Helmets: The Strategy of UN Military Operations. Dulles: Brasseys, 1998. HOWARD, Michael. Clasewitz: A Very Short Introduction. New York: Oxford University Press, 2002.

KENKEL, Kai Michael. Cinco Gerações de Operações de Paz: de "tênue linha azul" a "pintar um país de azul". Revista Brasileira de Política Internacional, Vol. 56, $\mathrm{n}^{\circ} 1$, 2013. Disponível em: http://www.scielo.br/scielo.php?script = sci_arttext\&pid = S003473292013000100007\&Ing = en\&nrm = iso\&tlng = en. Acesso em: 11 nov. 2016. 
LA MAISONNEUVE, Eric. Metamorfosis de La Violencia. Ensayos sobre La Guerra Moderna. Buenos Aires: Fundación BankBoston: Grupo Editor Latinoamericano, 1998.

MIALL, Andrew D. In defense of Facies Classifications and Models. Journal of Sedimentary Research, Vol. 69, n 1, 1999, p. 2-5. Disponível em: http://www.jsedres. Sepmonline. org/content/69/1/2.full.pdf + html? sid = 79931900-5c8a-45da-b388-dedbed828dea. Acesso em: 12 dez. 2016.

MIGON, Eduardo Xavier Ferreira Glaser. Estudos da Paz e da Guerra: síntese da contribuição de Grotius e Bobbio. Coleção Meira Mattos - Revista das Ciências Militares, v. 2, p. 53-62, 2012.

NASSER, Filipe. Pax Brasiliensis: Projeção de poder e solidariedade na estratégia diplomática de participação brasileira em Operações de paz da Organização das Nações Unidas. In: KENKEL, Kai Michael; MORAES, Rodrigo Fracalossi de. O Brasil e as Operações de Paz em um mundo globalizado. Entre a tradição e a inovação. Brasília: IPEA, 2012. Cap. 8, p. 213-242.

OSMAN, Mohamed Awad. The United Nations and Peace Enforcement: Wars, Terrorism and Democracy. Burlington: Ashgate, 2002.

PACHECO, Fabio Cordeiro; MIGON, Eduardo Xavier Ferreira Glaser. O Brasil na MINUSTAH influenciando o Brasil no Cone Sul: evidências preliminares da contribuição da diplomacia militar à inserção soberana. Coleção Meira Mattos - Revista das Ciências Militares, v. 7, p. 131-137, 2013.

PEDERSEN, Susan. The Guardians: The League of Nations and the Crisis of Empire. Oxford: OUP, 2015.

PENNA, Rodrigo Moreira. Brahimi + 10: an approaching decade of political challenges and the echoing lessons from the UN Transitional Administration of East Timor. Revista Carta Internacional, Vol. 4, nº 1, 2009, p. 46-51.

PENNA FILHO, Pio. Segurança seletiva no pós-Guerra Fria: uma análise da política e dos instrumentos de segurança das nações Unidas para os países periféricos - o caso africano. Revista Brasileira de Política Internacional, Vol. 47, n 1, 2004.

PINHEIRO DA CUNHA, Rafael Soares; MIGON, Eduardo Xavier Ferreira Glaser; VAZ, Carlos Alberto Moutinho. A Liga das Nações: considerações sobre a participação brasileira, êxitos e óbices da predecessora da Organização das Nações Unidas. Revista de Ciências Militares, v. 2, p. 317-336, 2014.

REZENDE, Lucas Pereira; AZEVEDO, César Augusto Lambert de. Sobre o Sistema de Segurança Coletiva e a Legitimidade das Operações de Paz da ONU. Revista Carta Internacional, Vol. 6, $\mathrm{n}^{\circ}$ 1, 2011, p. 23-38. Disponível em:. Acesso em: 15 abr. 2017. RICHMOND, Oliver. United Nations Peace Operations and the Dilemmas of the Peacebuiding Consensus. International Peacekeeping, Vol. 1, n ${ }^{\circ}$ 1, 2004, p. 83-101. 
RIKHYE, Indar Jit; HARBOTTLE, Michael; EGGE, Bjoern. The Thin Blue Line: International Peacekeeping and its future. New Haven: Yale University Press, 1974.

SEITENFUS, Ricardo. De Suez ao Haiti: a participação brasileira nas Operações de Paz. In: AMORIM, Celso. O Brasil e a ONU. Brasília: FUNAG, 2008. Cap 2, p. 39-58.

SILVA, Francine Rossone. A Paz Liberal nas Operações de Peacebuilding - O 'local' e os limites da crítica. 98 fl. Dissertação (Mestrado em Relações Internacionais), Pontifícia Universidade Católica do Rio de Janeiro, Rio de Janeiro, 2012.

UNITED NATIONS. An Agenda for Peace: preventive diplomacy, peacemaking peacekeeping, 17 jun 1992. Disponível em: http://www.un.org/Docs/SG/agpeace.html. Acesso em: 12 abr 2017.

UNITED NATIONS. Department of Peacekeeping Operations. United Nations Peacekeeping Operations: Principles and Guidelines, 2008. New York: Disponível em: http://www. peacekeepingbestpractices.unlb.org/pbps/pbps/library/capstone doctrine eng.pdf. Acesso em: 01 abr 2017.

UNITED NATIONS. Department of Peacekeeping Operations. United Nations Peacekeeping Operations. Disponível em: http://www.un.org/en/peacekeeping/documents/ operations/l ist.pdf. Acesso em: 01 abr 2017.

UNITED NATIONS. Department of Peacekeeping Operations. United Nations Peacekeeping Operations. Disponível em: http://www.un.org/en/peacekeeping/documents/ operations/current.shtml. Acesso em: 01 abr 2017.

UNITED NATIONS. Department of Peacekeeping Operations. United Nations Peacekeeping Operations. Disponível em: http://www.un.org/en/peacekeeping/resources/statistics/ contributors.shtml. Acesso em: 01 abr 2017.

UNITED NATIONS. Report of the Panel on United Nations Peace Operations. Disponível em: < http://www.un.org/peace/reports/peace_operations > Acesso em: 25 mar 2017.

WILLIAMS, Paul. Lições aprendidas com as operações de paz em África. Centro de Estudos Estratégicos de África. n 3, 2010. Disponível em: http://www.africacenter. org. Acesso em: 12 fev. 2017. 